\title{
Discussion on Ways and Methods to Improve the Work Efficiency of Teaching Secretary
}

\author{
Youwen Zhang \\ Sichuan information technology College \\ 237686626@qq.com
}

\begin{abstract}
In the new period, the college teaching secretary should have good political and ideological quality, professional ability, organization and management ability, and the ability to use office automation equipment. Strengthening the teaching secretary ability is conducive to improving the level of teaching management in colleges and universities, which may enhance the abilities of students as well. This paper analyzes the reasons that affect the efficiency of teaching secretary, and puts forward a series of methods to improve the efficiency of the work of the secretary.
\end{abstract}

Keywords: Teaching secretary; ability; working efficiency.

\section{Introduction}

College teaching secretary is the most basic staff of college teaching management who is easy to be ignored, but the role in teaching management cannot be ignored. From another perspective, the teaching secretary's work ability will directly or indirectly affect the college teaching management order. Because all the functional departments are related with the teaching secretary. These departments include teaching dean, dean's office, the office of general affairs, teachers and students etc. In this work circle, the teaching secretary needs to coordinate various relations and deal with a lot of tedious works. So how to improve the working ability and efficiency of the teaching secretary is the question that we should think about for a long time.

\section{Quality Requirements of Teaching Secretary}

Thought is the forerunner of action. As a teaching secretary, first of all should have a high ideological and political quality and love the teaching management work. With their own words and deeds, they should influence the students, guide students, students and students infected with education. Teaching secretary has a wide range of work which has large content, big responsibility, and complex routine. It requires the teaching secretary should have a strong sense of dedication and responsibility.

The teaching secretary should also be aware of some of the relevant knowledge, such as psychology, public relations, administrative management, management of higher school science and other scientific theory. And with these knowledge, the teaching management services can be served in a broader field.

With the development of science and technology, office modernization, information technology, networking and digitalization change the school's teaching management modes. The teaching secretary's work and service methods should have undergone fundamental change, to adapt to the new situation and grasp the new technology. Under the current conditions, teaching secretary should be fully aware of the importance of these modern management methods in improving office efficiency, especially the use of network resources.

School work should be based on teaching, therefore, teaching management is the central link of school management. One of the most important functions of the teaching secretary is to help the leader to carry on the teaching management. First of all, the teaching secretary needs to collect relevant teaching information and conduct research and analysis on it. At the same time, the teaching secretary can guide and adjust their work according to the relevant teaching information to improve the teaching quality. 
In addition, the teaching secretary should have a sound psychological quality. Teaching secretary status is special and the role is complex. Therefore, the teaching secretary should have a higher level of psychological quality. It is not only necessary to have a high sense of responsibility and self-confidence, which can take the initiative to adapt to the environment changes, but also a good emotional state. At the same time, there should be a strong will power to overcome difficulties, setbacks, and failures with enough courage and confidence. In addition, the teaching secretary also need to do the correct understanding and evaluation of their own, with strong interpersonal skills.

\section{Reasons for Affecting the Efficiency of Secretary Work}

\subsection{Complexity of Work.}

The workload of teaching secretary is very large. The first job is the teaching management of each student from the entrance to the graduation, including student registration, student information, on-line teaching evaluation, registration examinations, test scores, graduation thesis, graduation qualification and half-way there may be electives, corrosion test, make-up exam, rehabilitation, suspension, resumption and so on. The second work is on class management work of teachers. Detailed work consists of formulating the talent training scheme, curriculum information input, setting commencement program, reporting the exam arrangement, paper marking and archiving. From the content point of view, the main work of students teaching is undertook by the teaching secretary. This work has certain regularity and abruptness and the content is relatively cumbersome. From the point of working time, the teaching secretary's work can easily be affected by a lot of work, resulting in a multitude of things which will eventually affect the quality of the work.

\subsection{Possibility of Teaching Accidents in the Work.}

Teaching accidents are easy to happen in the teaching secretary work in colleges and universities. In the teaching management work, each work cannot be ignored, especially in all kinds of classes and examination notice. Because a lot of notification and information have time limit and once missed, there is no way to remedy. A lot of things are related to the vital interests of teachers and students, which does not allow you to make any mistakes, otherwise there will be a teaching accident. Teaching secretary is always in a tense working environment and works carefully. They often fear of teaching accidents. In this state of intense work and environment, the teaching secretary's psychological quality will be greatly affected, which will finally affects the working efficiency.

\subsection{The Quality and Ability of Teaching Secretary is not Neat.}

The structure of the teaching secretary is generally composed of three parts, the first is the outstanding graduates; the second is the graduate after appointment; the third is the original staff transferred to the secretary position after the cancellation of some departments. In this way, the quality of the secretary in the same position will be different because of the different cultural background. This is mainly reflected in the understanding ability of teaching secretary work. Whether the teaching secretary can correctly convey the task of each department is very important. In terms of capacity, most of the teaching secretary did not participate in the training of teaching secretary work before the job. During the work, they are circulated by the trivial work just in order to cope with them without any summary and research. Continuously for a long time, the teaching secretary will be tired of this boring work and there is no innovation and insight of the work. Without any summary of the work, the efficiency of the work can hardly be improved.

\section{Measures to Improve the Work Efficiency of Teaching Secretary}

In order to improve the efficiency of the teaching secretary, attentions on the quality of the teaching secretary should be paid. Although there are individual differences, but from the functional requirements, there are still a lot of common points. Overall, the author believes that the following basic methods can be taken. 


\subsection{Self-education and Knowledge Update.}

If there is no knowledge update, it is difficult to achieve the innovation of work. On the one hand, colleges and universities should create conditions of self-study and full-time studies for the teaching secretary and expand the teaching secretary's knowledge, so that they are not only familiar with the basic knowledge of the professional but the idea of modern teaching management will be applied to practice. In the use of modern management methods and modern management technology, it is necessary to let them know the other related professional knowledge, and constantly improve the knowledge structure in the practice of teaching management. On the other hand, the teaching secretary should learn hard, forge ahead and create favorable conditions for the individuals to do their jobs, forming a virtuous cycle of new knowledge continuously radiation effect.

\subsection{Cultivation of Innovative Thinking.}

Like the other works, the teaching secretary's work also need to be innovative. No innovation, no development, no innovation, no innovation work. Based on the service, assistance and coordination work, teaching secretary needs to give full play to their subjective initiative to work tasks, objectives and methods have their own independent thinking. In the course of teaching management activities, the competent leaders often consult the teaching secretary for advice and suggestions. At this time, the recommendations of teaching secretary should not only be able to express the idea of leadership, but also have new ideas and dare to break through the thinking of leadership block. This makes the proposal more innovative and can further improve the leadership of the decision-making

\subsection{Strengthen the Ability of Independent Coordination and Organization.}

Assisting leaders to do a good job is an important task of teaching secretary. But in daily work, leaders cannot hands-on all the things. Teaching Secretary needs to organize and coordinate a lot of work by themselves. Whether the personnel in this department can be organized and coordinated well by the teaching secretary and the department can be well operated will directly influence the realization of the leadership decision-making. Therefore, it is an important symbol to strengthen the independent coordination and organization ability of the teaching secretary in the ordinary work.

\subsection{Cultivate the Spirit of Professionalism.}

Professionalism is the driving force to enhance the quality of teaching secretary. Only when a man knows his own work, will he be inspired by endless power. The core of dedicated spirit is to serve the people by heart and put the sprit into practice.

\subsection{Enhance the Expression Ability of Language and Writing.}

Teaching secretary's work involves providing information, reports, instructions, teaching information to the leaders and conveying the information to the following staff about the superior instructions, notice, etc. The level of language using ability and writing ability also reflects the level of comprehensive quality of a teaching secretary. Therefore, the teaching secretary should consciously strengthen their oral language expression ability and writing ability

\section{Summary}

The work function of the teaching secretary is gradually enriched and developed with the development of the educational undertaking in colleges and universities. Only when the teaching secretary is equipped with the above quality, will he or she become an excellent talents for the college teaching management. 


\section{Reference}

[1] Sun Hongwei. The Quality Cultivation of the College Teaching Secretary's Function Realization [J]. Journal of Zhejiang Gongshang University. Vol. 75(2005) No.6.

[2] Ding Meifang. Talking about the quality of teaching secretary in colleges and universities and the ways of improving the work efficiency [J]. Journal of West Anhui University, Vol. 20(2004) No.1.

[3] Wang Xiufan. Elementary discussion on function,work characteristics and quality requirement of teaching secretary in institutions of higher education [J]. Journal of Shenyang Institute of Engineering, Vol. 6(2010) No.3. 